\title{
Short Communication: Fish diversity and its relationship with environmental variables in Kamala River, Nepal
}

\author{
SUMNIMA GHIMIRE ${ }^{1,2}$, NARAYAN PRASAD KOJU ${ }^{3,4, \boldsymbol{v}}$ \\ ${ }^{1}$ Naya Aayam Multi-Disciplinary Institute. Gokarneshwor-7, Jorpati, Kathmandu 44600, Nepal \\ ${ }^{2}$ Department of Environmental Science, School of Science and Technology, University of Northampton. Northampton NN1 5PH, Northamptonshire, \\ United Kingdom \\ ${ }^{3}$ Center for Postgraduate Studies, Nepal Engineering College, Pokhara University. Bhaktapur Rd, Changunarayan 44801, Nepal. \\ vemail: npkoju.2003@gmail.com \\ ${ }^{4}$ Department of Psychology, University of Washington. 1410 NE Campus Parkway, Seattle, Washington 98125, United States
}

Manuscript received: 31 August 2021. Revision accepted: 18 October 2021.

\begin{abstract}
Ghimire S, Koju NP. 2021. Short Communication: Fish diversity and its relationship with environmental variables in Kamala River, Nepal. Biodiversitas 22: 4865-4871. Kamala River originates from the lower part of the Mahabharat range and flows through inner to outer Terai, providing a broad range of ecosystem services; provisioning, regulating, supporting, and cultural. However, the information regarding the environmental factors and species diversity in the river is not available enough. Hence the study aimed to explore baseline information on the diversity and abundance of fish and their relation to environmental variables. The fish diversity was assessed in five sections of Kamala River and correlated with different environmental variables. The study was carried out during September-October 2019, marking the post-monsoon season of Nepal. Fish samples were collected using cast nets, and physiochemical parameters were analyzed onsite and in the laboratory. Altogether 19 freshwater fish species belonging to 5 orders, 8 families, and 15 genera were recorded. Cyprinids were the most dominant in the river, while Channids, Mastacembelids, Botiids, Sisorids, Gobiids were represented less. The Redundancy Analysis (RDA) ordination method revealed that species variation was correlated with temperature, Electrical Conductivity (EC), Total Dissolved Solids (TDS), and nitrate. Nonetheless, different river sections were disturbed due to mining, deforestation, and construction activities, which could pose a real threat to fish diversity and population, and other aquatic organisms.
\end{abstract}

Keywords: Correlation, fish species, Kamala River, water parameters

\section{INTRODUCTION}

Globally, about $97.5 \%$ of the total area is covered by ocean and seas, whereas only $2.5 \%$ constitute freshwater resources. Moreover, a large volume of freshwater exists in glaciers and snow cover, limiting water availability for humans. The spatial and temporal distribution of fresh water on the Earth's surface is greatly uneven stored in rivers, ponds, lakes, streams, and shallow aquifers. Despite the less area coverage, freshwater ecosystems provide a diverse and broader range of habitats with varying complexity (Wrona et al. 2013). They support a diversity of aquatic species that are adapted to living in moderate to extreme environments. Global freshwater ecosystems constitute about 100,000 species, out of which 13,000 are strictly freshwater fish species, majorly found in lakes and rivers (Leveque et al. 2008; World Wildlife Fund 2021). Water systems, especially rivers, have always remained a central feature of social and economic development. However, dependency on these resources for domestic, industrial, and agricultural purposes along with fish farming, in the long run, has altered the physical habitat and water chemistry of the system. In recent times, the freshwater system has become one of the most endangered habitats in the world primarily due to pollution, human development, and climate change (World Wildlife Fund 2021). Human impacts to freshwater habitats such as landuse changes, over-abstraction of water and river sediments, and chemical inputs have significantly altered water quality and its biodiversity (Mohd Izam et al. 2021).

Nepal, rich in water resources, comprises about 6,000 rivers and rivulets, with Koshi, Karnali, and Gandaki, being the country's major river systems. Based on the size, origin, and flow of nature, the rivers in Nepal can be classified as large, medium, or small rivers originating from Higher Himalayas, Mahabharat hills, and Siwalik-Churia hills, respectively (Adhikari 2013; NDRI and CSIRO 2016). Himalayan rivers fed by snow and glaciers carry large discharges even during dry seasons. The medium rivers generally experience monsoon discharge of $2000 \mathrm{~m}^{3} / \mathrm{s}$ to $8000 \mathrm{~m}^{3} / \mathrm{s}$ causing chances of flooding in the Terai, although they hold significantly less water during other parts of the year (Adhikari 2013). Likewise, Churia Rivers have almost no flow during dry seasons; however, it creates flash floods during monsoons (NDRI and CSIRO 2016).

The rivers differ morphologically in their origin, flow magnitude, and sediment load (Adhikari 2013). Based on these characteristics, their potentiality in providing different ecosystem services and habitats can be determined. The unique rivers in Nepal are affluent in 
aquatic biodiversity that host about 252 fish species from different climatic zones (Adhikari 2013; Shrestha 2019). Fish, an essential component of all aquatic ecosystems, are equally the most ignored and threatened aquatic fauna. The attention for conservation of freshwater fishes still lacks despite their high scientific, recreational, and economic value and more accessible sampling procedures than other macroinvertebrates. Increasing human dependency on rivers for water supply has further led to qualitative and quantitative alteration of aquatic habitat affecting its species (Larka et al. 2010; Mohd Izam et al. 2021). Insufficient knowledge, less priority, and limited studies on aquatic biodiversity have resulted in the global declination of fish species (Gurung 2012). Therefore, fish species and habitat management has been significant challenges for different countries, including Nepal.

Diversity and the overall distribution of aquatic communities are significantly determined by the biochemical and environmental parameters of the system. A better understanding of these factors and the response of the ecosystem towards the environmental variables have been the central area of interest for environmentalists over time (Odulate et al. 2014). In the eastern Terai, the Kamala River is one of the major dependable and vital water assets for local people relying upon fisheries and agriculture for their livelihood. Despite being one of the major rivers in Nepal, Kamala is poorly known for its water quality, species richness, and other environmental factors. Therefore, the study assessed the fish diversity and its relation to environmental factors in Kamala River, Nepal, which may bridge the gap, providing baseline information on the diversity of fish fauna and associated environmental variables.

\section{MATERIALS AND METHODS}

\section{Study area}

The study was carried in Kamala River in SeptemberOctober 2019. Kamala is one of the medium rivers that originate from the lower part of the Mahabharat Range, at an elevation of $1200 \mathrm{~m}$ (latitude $27^{\circ} 15^{\prime} \mathrm{N}$ and longitude $85^{\circ} 57^{\prime}$ E) near Maithan, Sindhuli district of Nepal (Figure 1). The river covers two major ecological zones of the country, flowing from mid-hills to the lowlands of Terai. Kamala is fed by seasonal rainfall, springs, and groundwater with enough discharge during monsoons and shallow flow during dry seasons (NDRI and CSIRO 2016). Flowing southerly from Sindhuli, Kamala passes through Nepal's Udayapur, Dhanusha, and Siraha districts and enters Madhubani district in Bihar, India. The river becomes more expansive with entering the Terai plain as they start meandering after the Bhabar zone (Adhikari 2013). The total length of the river is $328 \mathrm{~km}$, with a catchment area of $7232 \mathrm{~km}^{2}$, in which $2744 \mathrm{~km}^{2}$ lies in Nepal and the rest in India. More than $60 \%$ of the total water catchment that can be studied and acted upon lies below $500 \mathrm{~m}$ (Wagner et al. 2007; NDRI and CSIRO 2016).

Geologically, the river basin is composed of alluvial detritus and a constitution of clay, sand, silt, gravel, and some boulders. The area experiences hot and humid summers and cold and dry winters. The average annual rainfall in the basin is about $1681 \mathrm{~mm}$, occurring highest during June, July, and August. Due to its unique geology and climate, the river supports a diversity of warm-water fishes, providing a more significant opportunity to locals through fisheries.

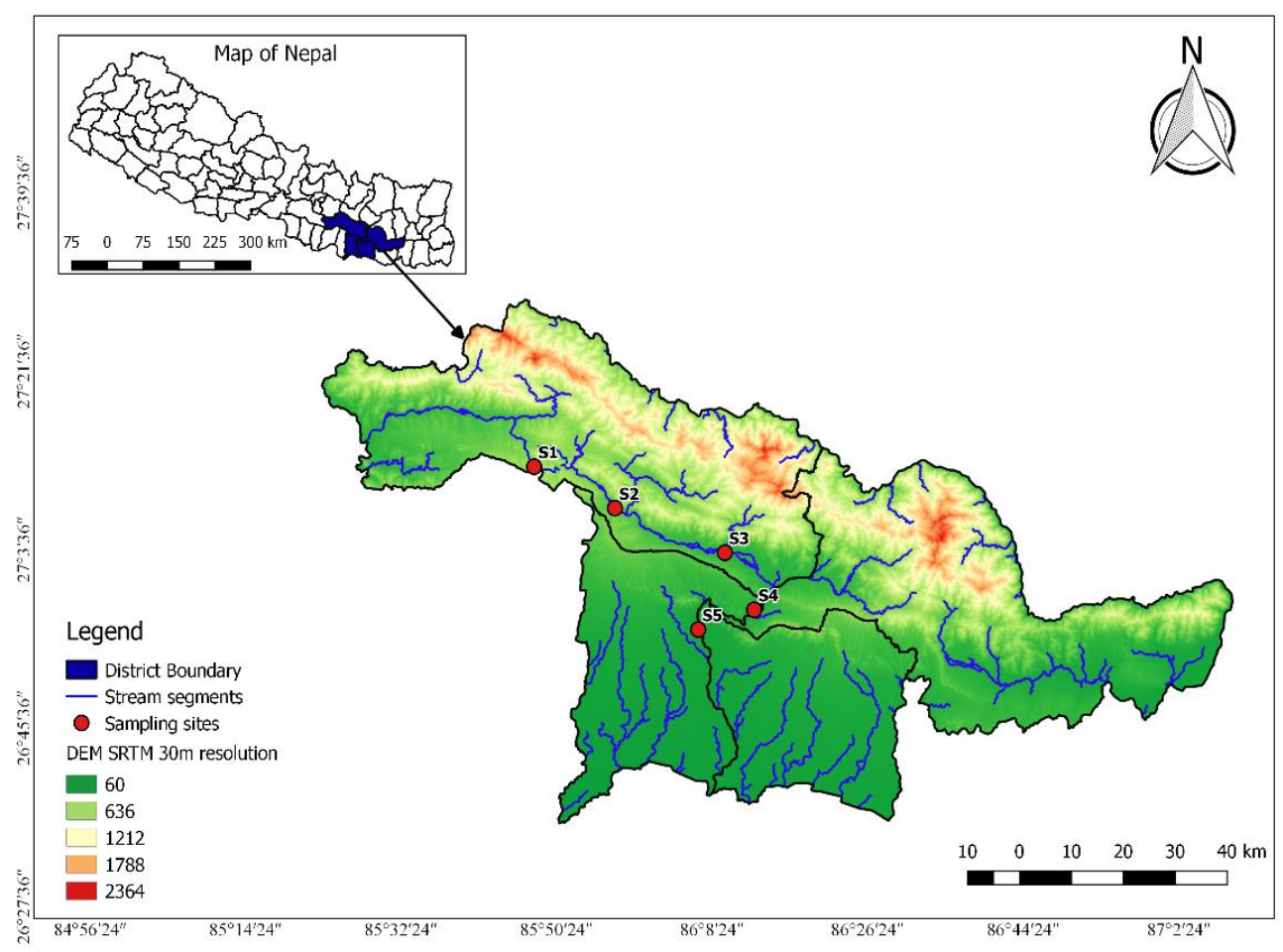

Figure 1. Study area and sampling sites in Kamala River basin, Nepal 
Table 1. Sampling sites in the Kamala River, Nepal

\begin{tabular}{lcccc}
\hline \multicolumn{1}{c}{ Site location } & Sampling points & Latitude & Longitude & $\begin{array}{c}\text { Elevation } \\
(\mathbf{m} \text { asl.) }\end{array}$ \\
\hline Tintale, Kamalamai, Sindhuli & KA1 & 27.16908 & 085.88282 & 464 \\
Bhiman, Kamalamai, Sindhuli & KA2 & 27.09402 & 085.98258 & 331 \\
Sirthauli, Dhudhauli,Sindhuli & KA3 & 27.01140 & 086.19254 & 193 \\
Dhansari-Belsot, Katari, Udayapur & KA4 & 26.91360 & 086.24495 & 135 \\
Kamala barrage, Dhanusha & KA5 & 26.88436 & 086.13494 & 87 \\
\hline
\end{tabular}

Table 2. Lab analysis of certain parameters

\begin{tabular}{lll}
\hline Parameters & Unit & Test methods \\
\hline Ammonia & $\mathrm{mg} / \mathrm{L}$ & APHA, AWWA, WPCF (1985), 417 B \\
Nitrate & $\mathrm{mg} / \mathrm{L}$ & APHA, AWWA, WEF (2017), 4500-NO ${ }^{-}$B \\
Phosphate & $\mathrm{mg} / \mathrm{L}$ & APHA, AWWA, WEF (2017), 4500 P E \\
Turbidity & NTU & APHA, AWWA, WEF (2017), 2130 B \\
\hline \multicolumn{2}{l}{ Note:*NTU- Nephelometric Turbidity Unit }
\end{tabular}

\section{Sampling sites}

Total five sites, including upstream, midstream, and downstream of the river, were selected (Table 1) based on altitudinal range, feasibility, and accessibility. Using a dataset from United States Geological Survey (USGS), the Digital Elevation Model (DEM) of the study area was extracted, and the exact geographic coordinates of the sampling points were plotted in QGIS, version 2.18.11. Hereby, KA1, KA2 represent upstream sites, KA3, KA4 represent mid-stream sites, while KA5 represents the downstream site of the river (Figure 1).

\section{Fish sampling}

Fish samples were collected with the help of local fishermen using the cast net of radius 3.5 meters, with weight around the edge about 1.5 kilograms/ermeter and mesh size about 10 millimeters. Fish sampling was performed at each site, covering a 40-50 m river stretch in which about 30 samples counts were maintained. The fish trapped in the net were collected in a tray filled with water, in which few drops (1-2 ml) of clove oil were added to make the fish handling easier. Clove oil, a natural product, possesses no greater harm considering its doses and can be an effective anesthetic to immobilize fishes (Javahery et al. 2012). Afterward, species were distinguished based on their local names provided by fishermen and the locals. Also, their photographs were taken and identified using available field guide Shrestha (2019). For further identifications, 1-2 samples of each species were preserved in $10 \%$ formalin solution, whereas others were released back into the water. With proper tagging and labeling, the samples were brought to the laboratory of NAMI College, for further species-level identification.

\section{Environmental variables}

For this study, environmental variables were selected based on water parameters and habitat assessing factors such as velocity and substrate types.

River water quality was analyzed through the selection of various physicochemical parameters, including water temperature, $\mathrm{pH}, \mathrm{EC}$, TDS, nitrate, ammonia, phosphate, and turbidity. Some parameters such as water temperature,
$\mathrm{pH}, \mathrm{TDS}$, and EC were analysed in the field itself using $\mathrm{pH}$ meter, TDS EC meter 2 in 1 Set Kit, Water Quality Tester Temperature with 0-14 pH Measure Range, 0-9999ppm Automatic Calibration meters by Homtiky, 2015. For further physiochemical analysis, water samples from each site were collected in a sampling bottle of $1000 \mathrm{ml}$ and stored immediately into the icebox. The samples were then transported to the lab of a scientific and national nongovernmental organization, Environment and Public Health Organization (ENPHO), Kathmandu, Nepal. Here analysis on ammonia, nitrate, phosphate, and turbidity was carried out using the Standard methods (Table 2).

With these, the average velocity of running water was calculated using the float method, following Dobriyal et al. (2016), while the composition of river substrate in each sampling site was noted based on direct observation.

\section{Statistical analysis}

To calculate fish diversity, quantitative measurement was carried out using the Shannon diversity index $(\mathrm{H})$, following, Spellerberg and Fedor (2003). Also, the evenness index and Relative Abundance (RA) of individual species were calculated. A direct gradient analysis technique, RDA, was performed to analyse the effects of environmental parameters on the abundance of fish species. Before this, DCA was carried out to obtain standard gradient length and choose between linear or unimodal ordination methods that could be best suited for this study (Ayoub-Hannaa et al. 2013). RDA and PCA are similar linear methods but differ in presenting information about the variation in their factors. Unlike Principal Component Analysis (PCA), RDA is constrained that search for the best explanatory variables. These multivariate analyses were carried out in $\mathrm{R}$, using vegan library.

\section{RESULTS AND DISCUSSION}

During the study period, a total of 19 species belonging to 5 orders, 8 families, and 15 genera were recorded from five different sampling points in the Kamala River (Table 3 ). The upstream of the river, KA1 showed a record of 5 species in which Garra annandalei, Paracanthocobitis boris, Barilius barila were with higher abundance while Barilius bendelisis and Esomus danrica had lower abundance. Similarly, KA2 had the record of 8 fish species, out of which Barilius barila had the highest proportion of about $38.15 \%$, followed by Esomus danrica (6.69\%), B. bendelisis (5.50\%), Paracanthocobitis botia (5.26\%), Puntius terio $(3.46 \%)$ and Garra annandalei $(2.87 \%)$. 
Other species were Channa punctata and Channa orientalis that were only recorded in KA2.

Fish communities in the middle section of the river (KA3) recorded 8 species, in which Aspidoparia morar and Macrognathus zebrinus were recorded only in this site. Likewise, sampling site KA4, situated at the difference of $45 \mathrm{~m}$ elevation from the barrage showed the record of 6 species in which Macrognathus lineatomaculatus was specific to the site. With the decreasing elevation, the lowest section of river, KA5 revealed 13 species, including Botia lohachata, Lepidocephalus guntea, Labeo fimbriatus, Amblypharyngodon mola, Glyptothorax alaknandi, Salmostoma bacaila and Glossogobius giuris that were newer and specific in downstream, below the barrage.

Out of the total recorded species, three were common to all the sites. Barilius barila was dominant in the river with a relative abundance of $38.15 \%$. Despite Barilius modestus being specific to midstream sites, the species showed the higher relative abundance of $32.29 \%$ at KA3 and KA4, respectively. Cypriniformes had the highest number of species (68\%), followed by Anabantiformes (11\%), Synbranchiformes (11\%), Gobiiformes (5\%), and Siluriformes (5\%) (Table 3).

KA5 had the highest species richness and evenly distribution out of all sites, suggesting the fish community to be most diverse at this site (Table 4). Similarly, despite the lower taxa richness, KA1 showed the frequency of recorded species to be most even compared to other sites, leading the Shannon diversity index to be higher for KA1 than KA2, KA3, and KA4 (as this index accounts for both abundance and evenness of species present). KA2 and $\mathrm{KA} 3$, with the same record for species richness, vary in terms of their abundance and distribution, which ultimately led to different scores for diversity and evenness indices. Moreover, KA4 was the least diverse among all the sites, with a very uneven occurrence of individual species.
For each site, the recorded water temperature was about $26^{\circ} \mathrm{C}$ to $27{ }^{\circ} \mathrm{C}$. Similarly, the $\mathrm{pH}$ value ranges from 7.2 to 8.31 , indicating river water to be slightly alkaline. With that, the values of EC were highest in KA4, followed by KA5, KA3, KA2, and KA1. The total dissolved solid content ranges between $41 \mathrm{ppm}$ to $187 \mathrm{ppm}$. The nitrate, phosphate, and ammonia content varied for each site, whereas turbidity remained less than 1NTU for all sites. All the parameters were within the range for supporting healthy fish communities in the river (Table 5).

The relationships between fish species and environmental variables were explained using RDA ordination (Figure 2). The set of explanatory variables selected for the analysis were a range of environmental parameters, including water temperature, $\mathrm{pH}, \mathrm{EC}$, TDS, nitrate, ammonia, phosphate, and velocity. RDA was chosen to summarize the linear relation of fish taxa over environmental variables as the gradient length obtained by DCA was less than the prescribed range $(<2.5)$. The first two axes of the DCA explained $57 \%$ and $27 \%$ of species variance, respectively. Similarly, the arrows indicate biplot scores for constraining variables (Temp, EC, TDS, and nitrate). Other variables, including $\mathrm{pH}$, ammonia, phosphate, and velocity, are absent in the plot indicating their minimal or no association with the fish.

Table 3. Summary on fish taxa richness and values of shannon diversity and evenness indices from each site

\begin{tabular}{lccc}
\hline Sites & $\begin{array}{c}\text { Fish taxa } \\
\text { richness }\end{array}$ & $\begin{array}{c}\text { Shannon diversity } \\
\text { index }\end{array}$ & $\begin{array}{c}\text { Evenness } \\
\text { index }\end{array}$ \\
\hline KA1 & 5 & 1.42 & 0.882 \\
KA2 & 8 & 1.04 & 0.50 \\
KA3 & 8 & 1.27 & 0.61 \\
KA4 & 6 & 0.66 & 0.36 \\
KA5 & 13 & 2.26 & 0.881 \\
\hline
\end{tabular}

Table 4 Summary on recorded species and their abundance in Kamala River

\begin{tabular}{|c|c|c|c|c|c|}
\hline Order & Family & Scientific name & $\begin{array}{c}\text { IUCN } \\
\text { red list } \\
\text { status }\end{array}$ & Individual count per sites & $\begin{array}{c}\text { Relative } \\
\text { abundance } \\
(\%)\end{array}$ \\
\hline Cyprinifomes & Cyprinidae & Barilius bendelisis & $\mathrm{LC}$ & KA1: 2, KA2: 31, KA3: 6, KA5: 7 & 5.50 \\
\hline Cypriniformes & Cyprinidae & Garra annandalei & $\mathrm{LC}$ & KA1: 10, KA2: 3, KA3:4, KA4: 4, KA5:3 & 2.87 \\
\hline Cypriniformes & Nemacheilidae & Paracanthocobitis botia & $\mathrm{LC}$ & KA1: 9, KA2: 4, KA3: 8, KA4: 15, KA5: 8 & 5.26 \\
\hline Cypriniformes & Cyprinidae & Barilius barila & $\mathrm{LC}$ & KA1: 9, KA2: 16, KA3: 107, KA4: 24, KA5: 18 & 38.15 \\
\hline Cypriniformes & Cyprinidae & Esomus danrica & $\mathrm{LC}$ & KA1: 2, KA2: 50, KA5:4 & 6.69 \\
\hline Anabantiformes & Channidae & Channa punctata & $\mathrm{LC}$ & KA2: 1 & 0.11 \\
\hline Cypriniformes & Cyprinidae & Puntius terio & $\mathrm{LC}$ & KA2: 1, KA3: 14, KA4: 2, KA5: 12 & 3.46 \\
\hline Anabantiformes & Channidae & Channa orientalis & VU & KA2: 1 & 0.11 \\
\hline Cypriniformes & Cyprinidae & Barilius modestus & DD & KA3: 42, KA4: 228 & 32.29 \\
\hline Cyprinifomes & Cyprinidae & Aspidoparia morar & $\mathrm{LC}$ & KA3: 3 & 0.35 \\
\hline Synbranchiformes & Mastacembelidae & Macrognathus zebrinus & $\mathrm{LC}$ & KA3: 1 & 0.11 \\
\hline Synbranchiformes & Mastacembelidae & Macrognathus lineatomaculatus & DD & KA4:2 & 0.2 \\
\hline Cyprinifomes & Botiidae & Botia lohachata & $\mathrm{LC}$ & KA5: 21 & 2.51 \\
\hline Cyprinifomes & Cobitidae & Lepidocephalus guntea & $\mathrm{LC}$ & KA5:3 & 0.35 \\
\hline Cyprinifomes & Cyprinidae & Labeo fimbriatus & $\mathrm{LC}$ & KA5:4 & 0.47 \\
\hline Cyprinifomes & Cyprinidae & Amblypharyngodon mola & $\mathrm{LC}$ & KA5:3 & 0.35 \\
\hline Siluriformes & Sisoridae & Glyptothorax alaknandi & $\mathrm{LC}$ & KA5: 1 & 0.11 \\
\hline Cyprinifomes & Cyprinidae & Salmostoma bacaila & $\mathrm{LC}$ & KA5:7 & 0.83 \\
\hline Gobiiformes & Gobiidae & Glossogobius giuris & $\mathrm{LC}$ & KA5: 1 & 0.11 \\
\hline
\end{tabular}

Note: *KA1: Site1, KA2: Site 2, KA3: Site 3, KA4: Site 4, KA5: Site 5. *LC: Least Concern, VU: Vulnerable, DD: Data Deficient 
Table 5. Range of physio-chemical parameters

\begin{tabular}{lccccc}
\hline \multicolumn{1}{c}{ Physio-chemical parameters } & KA1 & KA2 & KA3 & KA4 & KA5 \\
\hline Water temperature $\left({ }^{\circ} \mathrm{C}\right)$ & $26 \pm 0.5$ & $26.2 \pm 0.2$ & $26.6 \pm 0.3$ & $26.8 \pm 0.7$ & $26.5 \pm 0.6$ \\
$\mathrm{pH}$ & $7.2 \pm 0.15$ & $8.30 \pm 0.2$ & $8.27 \pm 0.3$ & $7.98 \pm 0.4$ & $8.31 \pm 0.3$ \\
$\mathrm{EC}(\mu \mathrm{S} / \mathrm{cm})$ & $89 \pm 0.36$ & $236 \pm 1.5$ & $344 \pm 4.04$ & $395 \pm 3.4$ & $376 \pm 5.5$ \\
TDS $(\mathrm{ppm})$ & $41 \pm 0.45$ & $112 \pm 2$ & $161 \pm 3.2$ & $187 \pm 4.3$ & $174 \pm 4.9$ \\
Nitrate $(\mathrm{mg} / \mathrm{L})$ & $0.17 \pm 0.01$ & $0.18 \pm 0.02$ & $0.16 \pm 0.01$ & $0.19 \pm 0.04$ & $0.16 \pm 0.05$ \\
Phosphate $(\mathrm{mg} / \mathrm{L})$ & $0.08 \pm 0.01$ & $0.07 \pm 0.02$ & $0.07 \pm 0.01$ & $0.09 \pm 0.03$ & $0.08 \pm 0.03$ \\
Ammonia $(\mathrm{mg} / \mathrm{L})$ & $0.09 \pm 0.01$ & $0.18 \pm 0.02$ & $0.18 \pm 0.02$ & $0.44 \pm 0.18$ & $0.15 \pm 0.04$ \\
Turbidity $(\mathrm{NTU})$ & $<1$ & $<1$ & $<1$ & $<1$ & $<1$ \\
\hline
\end{tabular}

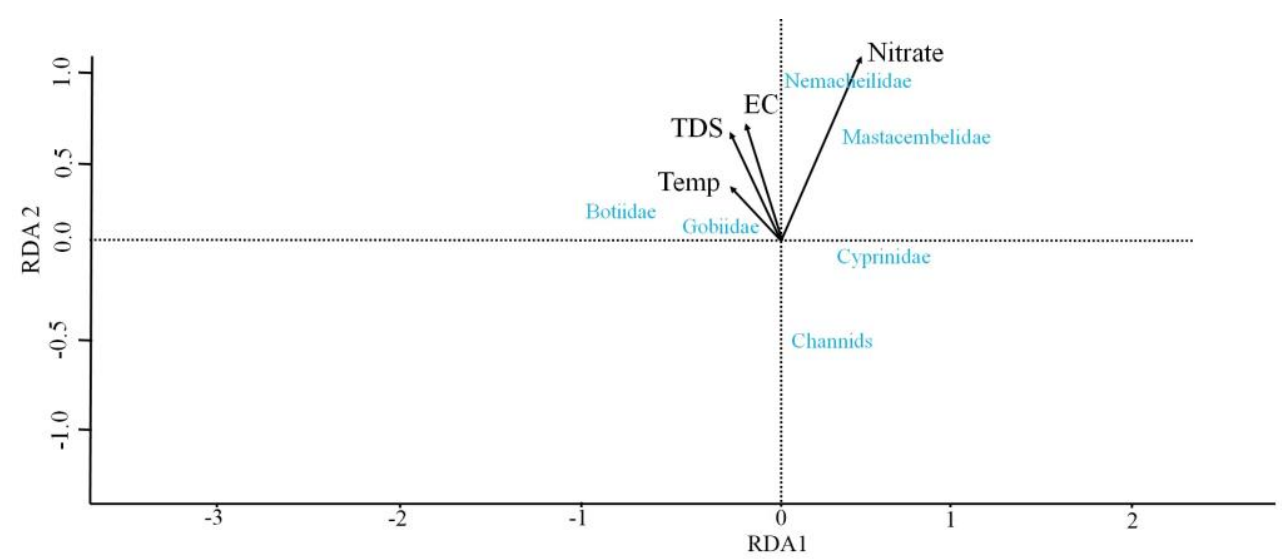

Figure 2. RDA ordination showing relations between fishes and environmental variables

From Figure 2, the first ordination axis shows that the temperature has a weak negative relation, whereas the second ordination axis shows that nitrate has a strong relation with fish species. Also, the diagram indicates a significant response of taxa over EC and TDS. The overlapping variables, TDS, and EC suggest their similar correlations with species. Moreover, Nemacheilidae and Mastacembelidae occurred closer in the plot, indicating their similar response to the environmental gradient. Nemacheilids and Mastacembelids were recorded at sites with comparatively higher nitrate, EC, and TDS values. Likewise, Botiidae and Gobiidae showed similar occurrence patterns at the downstream site, associated with higher temperature. The presence of Cyprinidae at origin indicates their abundance at all sites. While for Channids different occurrence pattern was observed. Henceforth out of all selected variables, fish distribution significantly correlated with temperature, nitrate, EC, and TDS.

The upper segment of the river (KA1) is comprised of 5 different species that belong to Cyprinidae and Nemacheilidae under the same order, Cypriniformes. A similar result was obtained for Tamor River in Eastern Nepal, where the result showed the record of Cyprinidae with Barilius shacra being the key species to the upper site (Shrestha et al. 2009). Despite being the uppermost sampling site, the values for diversity index and evenness index were quite high in Kamala River, which was different than that observed in Yangtze and Testa River in China (Bhatt et al. 2012; Kang et al. 2013). Kamala River originated at foothill has most of its accessible area below $500 \mathrm{~m}$. It does not experience extreme climatic conditions, lack of resources, or other environmental complexities at this site, which otherwise could have been the diversity limiting factors as mentioned by (Jaramillo-Villa et al. 2010).

Similarly, KA2 with open and deep water was dominated by Cyprinidae and Nemacheilidae under order Cypriniformes, followed by Channidae under order Anabantiformes. Fish taxa richness increased with the record of 3 newer species in which habitat tolerant Snakehead species (Channa punctata and Channa orientalis) were observed that were rare and specific to this site. Disturbances to the ecosystem caused by riverbed mining, nearby marketers, and settlers may have limited the distribution of these snakehead species and others, including Paracanthocobitis botia and Puntius terio. Species under Channidae family were recorded even from the deeper section of the Seti Gandaki River basin influenced by urbanization (Pokharel et al. 2018). Likewise, species such as Channa orientalis and Naziritor chelynoides recorded in lower segment of Mardi stream, Nepal showed a positive association with water temperature and negative association with water velocity, dissolved oxygen, and $\mathrm{pH}$ (Chapagain et al. 2021). In Lijiang River, China, fish richness and diversity showed significant relation to habitat type where most species under Cypriniformes had strong relationships with turbidity, depth, and wetted width (Huang et al. 2019). 
While in the Phewa Khola stream of Nepal, pools, and runs were primary habitats contributing to maximum fish diversity with water temperature, water velocity, and dissolved oxygen strongly correlating to fish assemblages (Limbu et al. 2021).

For the midstream section, KA3, cyprinids were dominant, followed by Nemacheilids and Mastacembelids, with Aspidoparia morar and Macrognathus zebrinus being specific to the site. Pebbles, stones, and gravel dominated the riverbed in the site, consisting of leaf substrate and algae, along the banks, which could have been a preferable habitat for these plankton feeding species (Cheng et al. 2019). The trend for diversity and evenness indices quite varied for KA2 and KA3 despite their equal number of species richness, which might be due to differences in the stressing factors (Inogwabini and Lingopa 2013). The sampling site KA3 being relatively farther from village settlements with fewer agricultural fields in the catchment might have comparatively lower pressure than in the upper section, KA2. Likewise, KA4 had the least diversity index and evenness index scores with only one species being newer and specific to the site. Macrognathus lineatomaculatus under the family Mastacembelidae, was new on record that was also reported from the Triyuga River in Nepal (Shrestha 2016). The distribution of fish taxa along this stretch was very uneven, which might have resulted from its eroded banks (leading to change in substrate composition), excessive mining for sand and stones, river channelization, and exploitation by nearby settlers. In Klawing River, Indonesia, the study revealed substrate variation and river mining for sand to adversely affect the ichthyofaunal pattern (Suryaningsih et al. 2018). The study in Tropical Australia showed high-order streams to be rich in diversity, yet streams being least protected and greatly influenced by human-induced disturbances (Januchowski-Hartley et al. 2011). Likewise, documenting the aspects of fish functional diversity from different climatic regions showed tropical freshwater fish diversity as the most vulnerable to human impacts that require great conservation focus (Vitule et al. 2017). In the Weihe River Basin of Northwest China, the distribution of fish species comprised of pollution tolerant cyprinids (Paramisgurnus dabryanus and Gobio coriparoides) from the catchment that was influenced by heavy sediment load and agricultural runoff (Cheng et al. 2019).

The downstream site of the river supports diverse fish communities, including important species of trout, carps, loach, and barbs. The site had an open river with a steady run near the barrage, which slightly narrowed down along the river stretch forming a riffle-pool sequence, providing diverse mesohabitat structures that may influence the fish composition (Calderon and An 2016). The downstream section often provides increasing food resources availability and greater niche separation resulting in higher biodiversity in the aquatic system (Bhatt et al. 2012; Sohail et al. 2014). Also, the presence of a low-head dam in the sampling site may have restricted the upstream movement of several species resulting accumulation of taxa near the dam, affecting diversity in KA4, like Giri River of Yamuna Basin, India (Rumana et al. 2015). Moreover, all the sampling sites provide a heterogeneous habitat to fish species with their riverbed comprising different materials such as pebbles, stones, gravels, and sand. Giakoumi and Kokkoris (2013) recorded the lowest diversity and evenness of species in sandy bottoms than in habitats with rocky bottoms. Most of the species that occurred in the river were small, common for medium-sized rivers, including Rapti and Babai (Shrestha 2019).

The ordination method revealed the response of fish species over variations in water temperature, EC, TDS, and inorganic nitrates. Along the elevation gradient, changes in environmental variables were observed, which influenced species distribution patterns. In River Swat, Pakistan, water parameters like $\mathrm{pH}, \mathrm{EC}$, and TDS showed negligible impact upon species abundance (Sohail et al. 2014). In Kamala, EC and TDS showed a significant positive relation with species distribution. Similarly, in the Reu River, a positive correlation with temperature, water depth, and negative correlation with $\mathrm{pH}$ and water velocity was observed for many fish compositions (Dhakal 2015). Likewise, fish diversity in the Bakraha River of Eastern Nepal had a positive correlation with temperature and a negative correlation with $\mathrm{pH}$ (Limbu et al. 2018).

Together with the selected range of parameters, the species richness and diversity of the riverine system could be affected by its flow pattern, water depth, wetted width, and substrate size (Huang et al. 2019). In parallel, microclimatic factors, land use patterns, and other humancaused disturbances may also strongly associate with fish assemblages (Suryaningsih et al. 2018).

In conclusion, the Kamala River showed richness in the biodiversity that supports small cyprinids species along with species of Mastacembelids, Botiids, Cobitids, Channids, Sisorids, and Gobiids. The downstream site shows the highest diversity of fish with the increasing availability of food resources and greater niche separation. The fish distribution showed a significant correlation with temperature, EC, TDS, and nitrate content. For the Kamala River, the richness and diversity of fish are affected by environmental and human-induced factors. The presence of riparian vegetation, diverse habitat structures, and riverine forest support richness and diversity in the fish, while barriers in movement and human encroachment adversely affect that. Research focusing on rigorous taxonomic studies combined with environmental aspects is crucial to providing baseline information for developing strategic conservation measures of the existing fish species, including the vulnerable ones in the river system. Some recommendations for successful conservation and management of fish fauna in the Kamala River are maintaining vegetation along the riverside to make the passes for fishes and control riverbank erosions and developing eco-friendly guidelines regarding bed mining activities.

\section{ACKNOWLEDGEMENTS}

We would extend our gratitude to the team of Smartphones4water (S4W), and Environment and Public 
Health Organization (ENPHO) for providing us with necessary field equipment and conducting lab analysis, respectively. This research is a part dissertation submitted to the University of Northampton, UK.

\section{REFERENCES}

Adhikari BR. 2013. Flooding and inundation in Nepal Terai: Issues and concerns. Hydro Nepal 12: 59-65. DOI: 10.3126/hn.v12i0.9034.

Ayoub-Hannaa W, Huntley JW, Fürsich FT. 2013. Significance of Detrended Correspondence Analysis (DCA) in palaeoecology and biostratigraphy: A case study from the Upper Cretaceous of Egypt. J Afr Earth Sci 80: 48-59. DOI: 10.1016/j.jafrearsci.2012.11.012.

Bhatt JP, Manish K, Pandit MK. 2012. Elevational gradients in fish diversity in the Himalaya: Water discharge is the key driver of distribution patterns. Plos One 8: e46237. DOI: 10.1371/journal.pone.0046237.

Calderon MS, An KG. 2016. An influence of mesohabitat structures (pool, riffle, and run) and land-use pattern on the index of biological integrity in the Geum River watershed. J Ecol Environ 40: 107-119. DOI: $10.1186 / \mathrm{s} 41610-016-0018-8$.

Chapagain N, Pandey N, Chitrakar P. 2021. Ichthyofaunal diversity in snow-fedMardi Stream of Gandaki River, Central Nepal. Biodiversitas 22 (5): 2940-2948. DOI: 10.13057/biodiv/d220559.

Cheng D, Zhao X, Song J, Sun H, Wang S, Bai H, Li Qi. 2019 Quantifying the distribution and diversity of fish species along elevational gradients in the Weihe River Basin, Northwest China. Sustainability 11: 1-16. DOI: 10.3390/su11216177.

Dhakal DP. 2015. Species Diversity and Distribution of Fish Community of Reu River. [Dissertation]. Tribhuvan University. [Nepal]

Giakoumi S, Kokkoris GD. 2013. Effects of habitat and substrate complexity on shallow sublittoral fish assemblages in the Cyclades Archipelago, North-eastern Mediterranean Sea. Mediterr Mar Sci 14: 58-68. DOI: $10.12681 / \mathrm{mms} .318$

Dobriyal P, Badola R, Tuboi C, Hussain SA. 2016. A review of methods for monitoring streamflow for sustainable water resource management. Appl Water Sci 7: 2617-2628. DOI: 10.1007/s13201016-0488-y.

Gurung TB. 2012. Native fish conservation in Nepal: Challenges and opportunities. Nepal J Biosci 2: 71-79. DOI: 10.3126/njbs.v2i0.7492.

Huang J, Huang L, Wu Z, Mo Y, Zou Q, Wu N, Chen Z. 2019. Correlation of fish assemblages with habitat and environmental variables in a headwater stream section of Lijiang River, China. Sustainability 11: 1-14. DOI: 10.3390/su11041135.

Januchowski-Hartley SR, Pearson RG, Puschendorf R, Rayner T. 2011 Fresh waters and fish diversity: Distribution, protection and disturbance in tropical Australia. Plos One 6 (10): e25846. DOI: 10.1371/journal.pone.0025846.

Jaramillo-Villa U, Maldonado-Ocampo JA, Escobar F. 2010. Altitudinal variation in fish assemblage diversity in streams of the central Andes of Colombia. J Fish Biol 76: 2401-2417. DOI: 10.1111/j.10958649.2010.02629.x.

Javahery S, Nekoubin H, Moradlu AH. 2012. Effect of anesthesia with clove oil in fish (review). Fish Physiol Biochem 38: 1545-1552. DOI: 10.1007/s10695-012-9682-5.

Inogwabini BI, Lingopa Z. 2013. Fish species occurrence estimates and human activities on the islands of the Congo River, Central Africa. Environ Biol Fish 96: 1-11. DOI: 10.1007/s10641-013-0136-4.

Kang B, Deng J, Huang X, Chen L, Feng Y. 2013. Explaining freshwater fish biogeography: history versus environment versus species personality. Rev Fish Biol Fish 23: 523-536. DOI: 10.1007/s11160013-9314-X.

Larka WS, Sarkar UK, Kumar RS, Pandey A, Dubey VK, Gusain OP. 2010. Fish diversity, habitat ecology and their conservation and management issues of a tropical River in Ganga basin, India. Environmentalist 30: 306-319. DOI: 10.1007/s10669-010-9277-6.
Leveque C, Oberdorff T, Paugy D, Stiassny MLJ, Tedesco PA. 2008. Global diversity of fish (Pisces) in freshwater. Hydrobiologia 595: 545-567. DOI: 10.1007/978-1-4020-8259-7 53.

Limbu JH, Shrestha OH, Prasad A. 2018. Ichthyofaunal diversity of Bakraha River of Morang district, Nepal. Intl J Fish Aquat Stud 6: 267-271.

Limbu JH, Subba S, Gurung JK, Tumbahangfa J, Subba BR. 2021. Correlation of fish assemblages with habitat and environmental variables in the Phewa Khola Stream of Mangsebung Rural Municipality, Ilam, Nepal. J Anim Divers 3: 27-36. DOI: 10.29252/JAD.2021.3.1.5

Mohd-Izam NA, Azman SN, Jonit E, Sallehoddin SMH, Khairul DC, Abidin MKZ, Farinordin FA. 2021. Freshwater ecosystem: A short review of threats and mitigations in Malaysia. Gading J Sci Technol 4 (1): 109-117.

Nepal Development Research Institute (NDRI) and Commonwealth Scientific and Industrial Research Organization (CSIRO). 2016. Kamala Basin.

Odulate DO, Samsons Y, Omoniyi IT. 2014 Multivariate analysis of fish species and environmental factors in marine coastal waters of the gulf of Guinea, Southwest Nigeria. Croatian J Fish 72: 55-62. DOI: 10.14798/72.2.729.

Pokharel KK, Basnet KB, Majupuria TC, Baniya CB. 2018. Correlations between fish assemblage structure and environmental variables of the Seti Gandaki River Basin, Nepal. J Freshw Ecol 33: 31-43. DOI: 10.1080/02705060.2017.1399170.

Rumana HS, Jeeva V, Kumar S. 2015. Impact of the low head dam/barrage on fisheries - A case study of giri river of Yamuna Basin (India). Transylv Rev Syst Ecol Res 17: 119-138. DOI: 10.1515/trser2015-0070.

Shrestha J. 2016. Fish diversity of Triyuga River, Udayapur District, Nepal. Our Nat 14: 124-134. DOI: 10.3126/on.v14i1.16452.

Shrestha J, Singh D, Saund T. 2009 Fish diversity of Tamor River and its major tributaries of Eastern Himalayan Region of Nepal. Nepal J Sci Technol 10: 219-223. DOI: 10.3126/njst.v10i0.2964.

Shrestha TK. 2019. Ichthyology of Nepal: A Study of Fishes of the Himalayan Waters. Kathmandu, Nepal.

Sohail M, Khattak MNK, Tauseef I, Korai AL, Shah A, Lashari KH. 2014 Ichthyodiversity in relation to physico-chemical parameters of River Swat. Sindh Univ Res J 46: 525-530.

Spellerberg IF, Fedor PJ. 2003. A tribute to Claude Shannon (1916-2001) and a plea for more rigorous use of species richness, species diversity and the 'Shannon-Wiener' Index. Glob Ecol Biogeogr 12: 177-179. DOI: 10.1046/j.1466-822X.2003.00015.x.

Suryaningsih S, Sukmaningrum S, Simanjuntak SB, Kusbiyanto. 2018. Diversity and longitudinal distribution of freshwater fish in Klawing River, Central Java, Indonesia. Biodiversitas 19 (1): 85-92. DOI: 10.13057/biodiv/d190114.

Vitule JRS, Agostinho AA, Azevedo-Santos VM, Daga VS, Darwall WRT, Fitzgerald, DB, Frehse FA, Hoeinghaus DJ, Lima-Junior DP, Magalhães ALB, Orsi ML, Padial AA, Pelicice FM, Petrere Jr. M, Pompeu PS, Winemiller KO. 2017. We need better understanding about functional diversity and vulnerability of tropical freshwater fishes. Biodivers Conserv 26: 757-762. DOI: 10.1007/s10531-0161258-8.

Wagner T, Sivapalan M, Troch P, Woods R. 2007 Catchment classification and hydrologic similarity. Geogr Compass 1: 901-931. DOI: $10.1111 / \mathrm{j} .1749-8198.2007 .00039 . x$.

World Wildlife Fund. 2021 Freshwater habitat-Overview (online).

Wrona FJ, Reist JD, Lehtonen H, Kahilainen K, Forsström L, Wrona FJ, Reist JD, Amundsen PA, Chambers PA, Christoffersen K, Culp JM, di Cenzo PD, Forsström L, Hammar J, Heikkinen RK, Heino J, Kahilainen KK, Lehtonen $\mathrm{H}$, Lento J, Lesack L, Luoto M, Marcogliese DJ, Marsh P, Moquin PA, Mustonen T, Power M, Prowse TD, Rautio M, Swanson HK, Thompson M, Toivonen H, Vasiliev V, Virkkala R, Zavalko S. 2013. Arctic biodiversity assessment: Status and trends in Arctic biodiversity. Freshw ecosyst 2013: 443-485 